\title{
Percepção e Vivência da Morte de Estudante de Medicina durante a Graduação
}

\section{Medical Undergraduate Student's Perception and Experience of Death}

\section{PALAVRAS-CHAVE}

- Morte.

- Educação de Graduação em Medicina.

- Cuidados Paliativos.

- Humanização da Assistência

\author{
Divanise Suruagy Correia ${ }^{\mathrm{I}}$ iD \\ Marias das Graças Monte Mello Taveira ${ }^{1} \mathbb{D}$ \\ Andrea Marques Vanderlei Ferreira Andrea Marques ${ }^{1}$ (iD \\ Raissa Ruperto Souza Chagas ${ }^{1}$ (iD \\ Cecilia Frazão Castro ${ }^{\mathrm{I}}$ (D) \\ Sandra Lopes Cavalcanti ${ }^{1}$ D
}

\section{RESUMO}

Introdução: o estudo da morte envolve a exploração que o indivíduo faz na busca de si mesmo. A Medicina tende a negá-la e controlá-la por meio de avanços tecnológicos e medicalização, o que leva ao pensamento de que o médico pode regular a duração dela. A morte é carregada de significados simbólicos e faz parte do processo de desenvolvimento humano, contudo muitas vezes é desconhecida do estudante de Medicina, o que leva ao temor pela indefinição do momento em que ocorrerá o encontro. Inerente às atividades do médico, há a crença de que poderá ser sempre evitada, sendo entendida como falha ou insucesso do tratamento, ou como desconhecimento do profissional, provocando ansiedade e cobrança tanto por parte da população como dos médicos. Este estudo objetivou relatar a vivência e percepção sobre a morte entre estudantes de Medicina. Método: trata-se se um estudo qualitativo, observacional, realizado com 50 alunos de três períodos de um curso de Medicina em Alagoas, em 2018. Usou-se um questionário com a seguinte pergunta aberta: "Após a vivência da morte durante o curso, o que mudou na sua atuação como estudante e na sua vida?". Os dados foram analisados manualmente em quatro etapas. A primeira fase consistiu na organização dos dados, procurando ideias que emergiram das respostas à questão norteadora, quando foi realizada a pré-análise, por meio de uma leitura aprofundada, na busca da criação das categorias, uma vez que elas não foram elaboradas previamente. A segunda fase correspondeu à elaboração da segunda planilha que armazenou as ideias explícitas (categorias provisórias) e implícitas (focos) com a identificação dos sentidos. A terceira fase procurou responder à pergunta da pesquisa por meio das unidades de registro, em que se relacionou a fala com o foco/tema e se identificou o sentido da inferência. A quarta fase compreendeu duas planilhas: uma com a interpretação dos focos e suas unidades de registros e outra com elaboração de síntese para cada foco. A vivência da morte pode acontecer em relação ao outro ou à própria morte, ocorrendo diferenças nos dois processos. Aqui abordagem concentrou-se na morte do outro e em como ela é vivenciada pelo estudante de Medicina durante a graduação. Resultados: Os dados obtidos resultaram em três categorias relacionadas à vivência da morte durante a graduação, refletindo o preparo ou não para lidar com o fenômeno. Cada categoria apresentou duas subcategorias: significação da morte, com as subcategorias "vida pessoal" e "vida profissional"; qualificação profissional, com as subcategorias "limites de atuação profissional" e "curso em relação à morte"; humanização, com as subcategorias "relação médico-paciente" e "cuidados paliativos". Conclusão: A pesquisa mostrou que os discentes modificaram sua visão da morte após a vivência durante o curso e que estão despertos para o tema, revelando a importância deste para sua formação e também a necessidade da ampliação de sua discussão durante a graduação. 


\section{KEY-WORDS}

- Death.

- Education Medical Undergraduate.

- Palliative Care.

- Humanization of Assistance.

\section{ABSTRACT}

Introduction: the study of death involves the exploration in the search of oneself. Medicine tends to deny death and control it through technological advances and medicalization, leading to the thought that the doctor can regulate the duration of the process. Death is full of symbolic meanings and it is an important part of the human development process, often unknown by the medical students, which makes them fearful for not knowing when this meeting is going to happen. It is inherent to the doctor's activities, believing it can be always avoided, being understood as a failure or unsuccessful treatment, or lack of knowledge by the professional, generating anxiety and demands, by the population and the doctors themselves. This research aims to report the experience and perception of death among medical students. Methods: it is a qualitative, observational study carried out with 50 students from three different semesters from a School of Medicine in the state of Alagoas, Brazil, in 2018. It was applied an instrument with an open question: After the experience of death during the course, what has changed in your performance as a student and in your life? The data was analyzed manually during four steps. The first phase consisted of organizing the data, looking for ideas that emerged from the answers to the guiding question, when the pre-analysis was carried out, through a deep reading aiming to define categories, since they had not been previously created; the second phase corresponded to the preparation of the second worksheet that stored the explicit and implicit ideas, the former being the temporary categories and the latter being the focus along with identification of the senses; the third phase sought to answer the study question through the record units, associating the speech to the focus/theme, identifying the sense of inference; the fourth phase was based on two spreadsheets, the first one with the interpretation of the main topics and their record units, and the second one with the creation of the synthesis for each focus. The experience of death may occur in relation to the other or to death itself, with differences between them. This research focus on the death of others and how undergraduate medical students experience it during the course, of which data resulted in three categories related to the experience of death during medical school, reflecting their capacity or not to deal with the phenomenon. Results: the three categories showed two subcategories, as follows: Acceptance of death, with subcategories in personal and professional life; Professional qualification with two subcategories: limits of professional performance and of the course in relation to death. The last category was Humanization, with two more subcategories: medical-patient relationship and palliative care. Conclusion: the research showed that the students modified their views about death during the course, and that they are aware of the topic, disclosing the value of this subject and also the need to discuss it during undergraduate school.

Recebido em 17/10/19

Aceito em 19/10/19

\section{INTRODUÇÃO}

Como o estudo da morte abrange questões que estão imbricadas na vida humana, quem almeja ampliar os conhecimentos sobre esse tema se envolve em uma exploração que é uma jornada na busca de si mesmo. A Medicina e as Ciências Humanas e Sociais contribuem para o estudo desse tema, apesar de ocorrer uma tendência de relegá-lo para fora do cotidiano e, dessa forma, afastá-lo de nossa presença, negando-o, esquecendo-o ou buscando controlá-lo por meio de avanços tecnológicos ${ }^{1}$. Por sua vez, a medicalização da morte leva ao pensamento de que o médico pode regular sua duração e, a despeito do conhecimento de que não pode suprimi-la, tenta fazê-lo quando nega sua existência no dia a dia ${ }^{2,3}$.

A morte é carregada de significados simbólicos e faz parte do processo de desenvolvimento humano ${ }^{2}$. Representa o poder sobre o qual não temos controle, sendo muitas vezes desconhecida do estudante de Medicina, o que leva ao temor pela indefinição do momento em que ocorrerá o encontro, geralmente relacionado ao fato do desconhecimento de como acontecerá e em que momento do vida. Como se trata-se de evento inerente às atividades do médico, existe a crença nesse meio de que ela poderá ser sempre evitada, sendo entendida como falha ou insucesso do tratamento, ou como desconhecimento do profissional, o que provoca ansiedade e cobrança tanto da população como dos médicos ${ }^{3}$.
Ser consciente da terminalidade vida é uma característica apenas dos humanos, como enterrar seus mortos e demonstrar conhecimento sobre o fenômeno, no entanto esse conhecimento não está relacionado a razões refletidas, intuitivas ou instintivas. Corpos são enterrados por questões simbólicas, o morto não é um cadáver qualquer. A morte não se limita apenas ao fim da existência física, ela acaba também com o ser social ao qual a coletividade atribui uma dignidade maior ${ }^{4}$.

A morte pode ser vista não apenas como o esgotamento dos órgãos e a finalização de seu funcionamento no corpo, traduzindo o fim da vida. Segundo estudiosos envolvidos com a física quântica, a visão da morte como fim da evolução do ser humano traz um conhecimento limitado, circunscrito aos cinco sentidos, e está relacionada à física newtoniana ${ }^{5,6}$. Essa visão apresenta seis postulados: 1 . só existe o mundo como percebido pelos cinco sentidos, 2. tudo na natureza tem começo e fim, 3. a vida começa no nascimento e na morte do indivíduo, 4. a morte se caracteriza pelo fim das sensações, 5. a vida individual é independente da vida no Universo e 6. com a morte cessam a evolução e o aprendizagem do indivíduo ${ }^{5}$.

Os teóricos da física quântica, ao afirmarem que a morte é uma transformação, abordam a vida de outra forma e informam que as pesquisas sobre consciência e compreensão da visão do mundo quântico representam o futuro da ciência sob um novo paradigma ${ }^{6}$. Quando

REVISTA BRASILEIRA DE EDUCAÇÃO MÉDICA

2 44 (1) : e013; 2020 
nos emocionamos, mobilizamos energias que as tradições espirituais denominam de prana, chi, ki ou energia vital, segundo a cultura de cada sociedade. Segundo Goswami ${ }^{6}$, o sentimento não é sensação; a sensação está somente relacionada ao sistema nervoso, enquanto o sentimento ocorre em conjunto com vários órgãos do corpo e, na verdade, não pertence ao corpo, sendo um movimento do corpo vital, energia que sentimos e que é denominada energia vital ${ }^{6}$.

Algumas religiões afirmam que a morte é a passagem de um estado de vida para outro, e outras apontam que ela é a mudança do estado de consciência. Nos últimos anos, por conta de alguns princípios da física quântica, os conhecimentos da ciência e da religião começaram a interagir, levando a expansão da compreensão do ser humano para além da dimensão biológica ${ }^{5,6}$. Essa ideia deve ser considerada principalmente quando se busca o alívio do sofrimento humano diante da morte ${ }^{5,7}$.

A dimensão entre o existencial e o transcendente é conhecida como dimensão espiritual. O ser humano apresenta diferentes dimensões, que são integradas pelo significado atribuído a cada uma delas. Às vezes se confunde a dimensão existencial com a espiritual, o que é uma verdade parcial, uma vez que a família, o trabalho e a religião podem apresentar ou não uma relação com o transcendente, Deus o Sagrado e o sobrenatural ${ }^{7}$.

Assim, é necessário diferenciar espiritualidade de religiosidade, apesar haver grande relação entre ambas. A religiosidade envolve dogmas, culto e doutrina que são partilhados pelas diversas religiões, enquanto a espiritualidade está entrelaçada com questões que transcendem os fenômenos sensoriais. Trata-se de questões referentes, por exemplo, ao significado e ao propósito da vida que buscam respostas nos permitam realizar uma reorganização interior e repensar os conceitos e as prioridades da vida ${ }^{8}$.

$\mathrm{O}$ processo educativo para a morte começa a acontecer nas universidades, principalmente com o advento do estudo dos cuidados paliativos ${ }^{9}$, embora ainda haja alguns vazios relacionados à tanatologia em algumas instituições no Brasil ${ }^{10}$. Dessa forma, como o fenômeno da morte para os médicos ainda é uma questão a ser muito discutida e esclarecida, devem-se ponderar os reflexos sobre a prática médica que ocorrem quando um paciente morre. A vida hospitalar está carregada de vivências do morrer, e, quando se considera o aspecto curativo tradicional da Medicina, observa-se que há dificuldades na assimilação filosófica dos cuidados paliativos que, muitas vezes, são rejeitados pelos familiares e vistos como uma forma não adequada de atenção ao paciente e consequente de aceitação da terminalidade da vida ${ }^{10}$.

Kübler-Ross ${ }^{11}$ estudou a morte e o morrer e expôs diversos sentimentos vivenciados por aqueles que encaram a proximidade da própria morte ou de familiares e amigos. A autora, em sua clássica obra Sobre a morte e o morrer, afirma que a forma de ver a morte como tabu é acompanhada da visão de algo trágico, o que impede que se observe a morte como natural, mesmo durante a infância, na juventude e na idade avançada. $O$ progresso da tecnologia e das conquistas científicas tornou os seres humanos capazes de desenvolver novas qualidades, no entanto, em relação à morte, continuam a apresentar um processo de defesa que se manifesta de diversas formas, desde medo da morte e até a incapacidade de prevê-la.

A angústia, a insegurança, o temor, o arrependimento, a culpa e a revolta são afetos que podem ser acompanhados da dúvida e da indagação sobre descuido na assistência ${ }^{12}$. Há muitos estudos sobre as reações dos profissionais da saúde perante a morte, o luto e as competências. Intervenções terapêuticas podem ser fundamentais na alteração dos cuidados oferecidos ao doente, aos familiares dele e aos profissionais envolvidos no processo de morte e luto, de modo a ajudá-los a transformar a visão limitadora da morte, aliviar o sofrimento e melhorar a qualidade de vida e do processo da morte ${ }^{12}$.

Assim, a morte continua sendo considerada um desafio para os que cuidam e tratam das enfermidades, entendendo-se também que docentes e discentes da área da saúde necessitam de formação mais acurada sobre o tema. Esse desafio ocorre tanto para a sociedade como para os educadores, em todos os níveis educacionais, ou seja, desde os ensinos fundamental e médio. Em todos os níveis da educação, percebe-se a necessidade de os educadores entrarem em contato com sua visão de morte e lutos, considerando sua influência em seus alunos, devendo haver espaços para emoções, sentimentos e comunicação ${ }^{13}$.

Alguns currículos de cursos superiores da saúde destacam as tecnologias e os medicamentos destinados à cura ou ao tratamento de enfermidades, o que reforça a formação dos profissionais voltada à defesa da vida e à batalha contra a morte. O ensino e a aprendizagem sobre o processo de morrer e a morte são desafiadores, principalmente quando se percebe o despreparo para discutir o assunto. Uma das limitações se insere na forma como o tema é abordado, ou seja, a morte é cogitada em uma esfera biologicista, representando um evento contrário à vida ${ }^{14}$

A graduação em Medicina é regulamentada pelas Diretrizes Curriculares Nacionais (DCN), que em 2014 incluíram a morte em seus conteúdos curriculares ${ }^{15}$. Por ser a morte uma constante no cotidiano dos profissionais da saúde, as DCN determinam a necessidade de compreender o fenômeno não só biologicamente, mas também social e emocionalmente, sendo assim uma das competências e habilidades específicas do médico, que deve ter esse aprendizado durante sua formação.

Portanto, a concepção de morte faz parte da educação médica e precisa ser mais discutida ante o despreparo discente e consequentemente de médicos em situações que envolvam lidar com a morte. Em algumas escolas médicas, despontam experiências positivas nesse sentido, principalmente no tocante à habilidade de comunicação entre médicos, pacientes e família. A comunicação entre o médico e seu paciente deve ser considerada um processo que pode influenciar a adesão ao tratamento e melhorar as relações interpessoais ${ }^{16}$. Comunicar enfermidades ameaçadoras à continuidade da vida, o que pode ser considerado uma má notícia, é uma vivência difícil para o médico e o estudante de Medicina que, muitas vezes, não sabem lidar com o sofrimento emocional do paciente e da família. A falta de uma comunicação adequada pode causar prejuízo a à relação terapêutica ${ }^{17}$.

Nos últimos tempos, surgiram diversos protocolos surgiram nos últimos tempos, todos com os mesmos procedimentos: preparação inicial, em que o médico rememora seus conhecimentos sobre a doença e seus cuidados; seleção de um local adequado para que a conversa ocorra; presença de pessoas que o paciente deseje; conversa franca e com compaixão; habilidade para lidar com o silêncio e os sentimentos que surgirem; planejamento de metas para momentos durante e após a conversa; revisão da compreensão do que foi conversado; e disponibilidade para dúvidas e/ou outros encontros que forem necessários ${ }^{16,17}$.

Um dos protocolos utilizados atualmente nas universidades brasileiras é o Setting up, Perception, Invitation, Knowledge, Emotions, Strategy and Summary (Spikes). Esse modelo de comunicação apresenta seis passos: $(\mathrm{S})$ preparar-se para o encontro, $(\mathrm{P})$ perceber o paciente, $(\mathrm{I})$

REVISTA BRASILEIRA DE EDUCAÇ̃̃o MÉDICA

3 44 (1) : e013; 2020 
convidá-lo para o diálogo, $(\mathrm{K})$ transmitir as informações, (E) expressar emoções e (S) resumir e organizar estratégias. Há ainda quatro objetivos principais: identificar o conhecimento do paciente e dos familiares sobre a situação como um todo, oferecer informações de acordo com o que o paciente e a família são capazes de ouvir, dar suporte a reações que podem advir e finalmente possuir um plano para atuar perante a situação ${ }^{17}$.

Por tratar-se de um ocorrência natural da vida humana, a morte é um fenômeno com que o médico se depara frequentemente, no entanto o debate sobre ela é muitas vezes considerado mórbido. Por conta disso, o assunto é sempre evitado, como se abordar tal tema fosse uma forma de atrair a morte, o que evidentemente leva à fuga da reflexão sobre o fato. Em contrapartida, ocorre cotidianamente o contato, por meio dos meios de comunicação, com imagens de horror e morte, seja em forma de documentários ou ficção ${ }^{18}$.

Com base no exposto, pode-se constatar a importância do tema na formação médica, e este artigo objetiva relatar a vivência e percepção sobre a morte entre estudantes de Medicina.

\section{MÉTODOS}

Trata-se de um estudo qualitativo, observacional, realizado com 50 alunos de três períodos (segundo, quarto e oitavo) de um curso de Medicina, em Alagoas, no ano de 2016.

$\mathrm{Na}$ pesquisa original, adotou-se como instrumento um questionário elaborado pelos pesquisadores com perguntas abertas e fechadas sobre a morte, que foi aplicado em sala de aula. Aqui se apresenta o resultado da análise de uma das perguntas abertas:

- Após a vivência da morte durante o curso, o que mudou na sua atuação como estudante e na sua vida?

Os dados foram analisados manualmente seguindo recomendações de Malheiros ${ }^{19}$. A primeira fase consistiu na organização dos dados, em que se identificaram as ideias que emergiram das respostas à questão norteadora. Nessa fase, realizou-se a pré-análise por meio de uma leitura aprofundada, com o objetivo criar as categorias, uma vez que elas não não foram elaboradas previamente. Essa fase corresponde à identificação da unidade de contexto. Para isso, todos os dados foram transcritos em uma planilha. Na primeira planilha, fez a transcrição dos depoimentos de forma ipsis litteris.

A segunda fase correspondeu à elaboração da segunda planilha que armazenou as ideias explícitas (categorias provisórias) e implícitas (focos) com a identificação dos sentidos, considerando os três princípios do método de Malheiros ${ }^{19}$. O primeiro princípio refere-se à exclusão, ou seja, quando um dado ou um conjunto de dados pertencer a uma categoria, automaticamente ele será excluído das demais. O segundo princípio está relacionado à pertinência: nesse caso, quando um dado não pode ser integrado a uma categoria por falta de escolha, é necessário que ele seja pertinente à categoria em que foi enquadrado. O terceiro princípio tem a ver com a objetividade: quando se liga um dado a uma categoria, é imprescindível que ele esteja claro para que não haja influência da subjetividade na organização dos resultados da pesquisa.

A terceira fase (terceira planilha) procurou responder à pergunta da pesquisa por meio das unidades de registro, em que se relacionou a fala com o foco ou tema. Essa fase teve como objetivo identificar a inferência obtida fazia sentido. Nesse momento, exemplifica-se no texto como se chegou ao resultado, que é a unidade de registro (uma palavra ou uma frase).

A quarta fase compreendeu a elaboração de duas planilhas. Na primeira, interpretamos os focos e suas unidades de registos, finalizando com a elaboração de síntese para cada foco. A segunda planilha dessa fase se refere à elaboração de ideias que correspondem às categorias e às suas respectivas subcategorias.

O projeto foi aprovado pelo Comitê de Ética e Pesquisa da universidade, sendo aprovado pelo Certificado de Apresentação para Apreciação Ética (CAAE), Processo $n^{\circ}$ 45959415.3.0000.5013, não havendo conflitos de interesse.

\section{RESULTADOS E DISCUSSÃO}

A vivência da morte pode ocorrer em relação ao outro ou a si mesmo, com diferenças nos dois processos. Este estudo aborda a morte do outro e identifica como ela é vivenciada pelo estudante de Medicina durante a graduação. Os dados obtidos resultaram em três categorias relacionadas à vivência da morte durante a graduação, refletindo o preparo ou não para lidar com o fenômeno.

As categorias identificadas foram significação da morte, qualificação profissional e humanização, que apresentamos no Quadro 1 com suas respectivas subcategorias.

\section{Significação da morte}

Essa categoria apresentou duas subcategorias, ou seja, significação na vida pessoal e na vida acadêmica e profissional. Como alguns discentes não haviam passado pelo processo da morte de forma próxima na família ou entre amigos, a vivência na graduação possibilitou a reflexão sobre o tema e a existência da proximidade da morte. Falar da morte nos espaços de ensino e trabalho médico traz olhares diversos, passando pelo suposto fracasso da área médica ${ }^{20,21}$.

\section{Significação na vida pessoal}

A significação da morte na vida pessoal vem relatada pelos pesquisados na forma de "passar a enxergar a morte como natural", dentro do processo da vida que é inevitável a todos seres vivos. A morte está enraizada no dia a dia da vida humana, e a consciência dela é uma das características da humanidade, uma vez que o ser humano é o único animal que tem a sensibilidade de conceituá-la e captá-la ${ }^{4}$. No entanto, apesar de certa, a morte aparece ainda nos dias atuais como um mistério e, por isso, vem provocando a busca de conhecimentos no sentido de melhor entendê-la.

\begin{tabular}{|c|c|}
\hline \multicolumn{2}{|c|}{$\begin{array}{c}\text { Quadro 1 } \\
\text { Categorias e subcategorias de análise }\end{array}$} \\
\hline CATEGORIAS & SUBCATEGORIAS \\
\hline \multirow{2}{*}{ Significação da morte } & Na vida pessoal \\
\hline & $\mathrm{Na}$ vida profissional \\
\hline \multirow{2}{*}{ Qualificação profissional } & Limites de atuação profissional \\
\hline & Limites do curso em relação à morte \\
\hline \multirow{2}{*}{ Humanização } & Relação médico-paciente \\
\hline & Cuidados paliativos \\
\hline
\end{tabular}

Fonte: elaborado pela autoras

REVISTA BRASILEIRA DE EDUCAÇÃO MÉDICA

4 44 (1) : e013; 2020 
Apesar de certa e por mais que se estude, os resultados das pesquisas realizadas pouco têm ajudado ante o muito que ainda é desconhecido sobre o fenômeno, que é temido por causar o desparecimento físico e a consequente anulação do ser, levando à dificuldade do sentido que lhe é dado ${ }^{4}$.

[...] ver a morte do paciente me fez perceber o quanto é difícil lidar com a morte (João, 20 anos).

Me tornei mais reflexiva, depois que vi o paciente falecer na enfermaria [...] (Isa, 21 anos).

Lidar com a morte exige entrar em contato com a terminalidade da vida material e a amenização das forças do ego, sendo um desafio para o enfrentamento das emoções de perda e desapego que ela carrega. Refletir sobre o fenômeno e assumir a dificuldade em lidar com ele possibilita ao estudante a mudança na forma de ver o fenômeno e lidar com ele, gerando uma maior aproximação e possibilitando deixar de negá-lo ao assumir sua existência e possiblidade no cotidiano.

Kübler-Ross ${ }^{11}$ identificou cinco estágios de uma paciente com doença terminal incurável. O primeiro estágio é a negação, quando não se admite o diagnóstico. A negação funciona como um anteparo às notícias inesperadas e chocantes, trata-se de uma defesa temporária que é substituída por uma aceitação parcial. A raiva encontra-se no segundo estágio, momento em que o paciente se torna intransigente e impaciente em relação às terapias propostas. O terceiro estágio refere-se à barganha, quando se busca uma nova tática com o propósito de aceitar a situação desde que se possa negociar com Deus o recebimento do milagre da cura.

O quarto estágio é o insucesso da barganha que traz a depressão, momento muito importante para cuidar de quem está morrendo. Existem nesse momento dois tipos de depressão: aquela que envolve as preocupações de quem quer deixar a vida organizada e a outra que leva em conta perdas iminentes. O quinto e último estágio traz a aceitação por quem teve ajuda e tempo para superar os estágios anteriores. KüblerRoss $^{11}$ descreve um grau de "tranquila expectativa" que não deve ser confundido com felicidade. Trata-se da fuga de sentimentos, do estado de profundo cansaço e da necessidade de aumentar as horas de sono. É nessa hora final que os familiares necessitam de compreensão e apoio.

\section{Significação na vida acadêmica e profissional}

Em relação a essa subcategoria, obtivemos as seguintes afirmações:

Tive de aprender a lidar com o fato de que a morte existe e que temos de tentar lidar com ela sem que esta afete o nosso trabalho, sendo que não é fácil (Maia, 22 anos).

Depois de tantos anos estudo e convivência no hospital, passei a encarar a morte com menos sofrimento e entender que nem sempre conseguiremos a cura (Paulo, 24 anos).

A visão que o estudante tem sobre a morte poderá determinar a disponibilidade interna, os valores, os conceitos e os preconceitos relacionados a ela e ao morrer. O entendimento da morte como uma condição intrínseca da vida é importante para o mundo, considerandose atitudes e competências notadamente entre os que lidam diretamente com ela em sua vida profissional. Os médicos e os estudantes de Medicina, em seu início de vida profissional, deparam-se com a responsabilidade de decidir sobre as condições de saúde e vida de seus pacientes ${ }^{13,14}$. Isso traz angústia e ansiedades quando eles não possuem subsídios necessários para encarar o ocorrido na vida acadêmica.

Muitos médicos não se sentem preparados para prestar cuidados de fim de vida ou se comunicar com os pacientes e as famílias sobre questões sensíveis relacionadas com a morte e o morrer. Os médicos geralmente atribuem sua falta de preparação a uma formação inadequada na escola de Medicina ${ }^{3,5,20,21}$. Verificou-se que os estudantes valorizam o preparo profissional para enfrentar a morte durante o curso, com a apreensão $e$ aplicação dos princípios dos cuidados paliativos, o que leva à compreensão dos limites do conhecimento da Medicina e da atuação do profissional médico perante a morte, despertando o sentimento de humanização no cuidado com ele próprio, com o paciente e com a família.

Isso remete à categoria qualificação profissional que apresenta as duas subcategorias descritas a seguir.

\section{Limites de atuação profissional}

Apesar de o tema da morte ser discutido há muito tempo e o assunto ser debatido em vários âmbitos, os médicos geralmente não se sentem capazes de enfrentar o processo, encarando a morte com sentimento de culpa, impotência e fracasso, embora sejam capacitados para lidar com doenças terminais ${ }^{21}$.

A Medicina prepara o profissional para lutar em favor da vida a todo momento, no entanto é necessário que o médico diminua sua onipotência e reconheça que a ciência tem limites ante as decisões que a vida traz. Isso proporcionará proteção para lidar com temores perante a morte $\mathrm{e}$ a culpabilização. Existe um compromisso entre o médico, o paciente e a família no sentido do cuidado e da cura, havendo a crença de que o médico tem o domínio sobre a vida e a morte, o que cria uma onipotência imaginária no profissional e provoca uma gratificação narcísica, que ajuda o profissional a superar seus temores de fracasso ante a morte ${ }^{22}$.

Nesse sentido, o médico oscila entre a sensação de tudo poder e a frustração de nada conseguir fazer diante dos imprevisíveis processos biológicos, e assim a piora do paciente constitui a destruição da construção imaginária de onipotência ${ }^{22,23}$. O médico deve enfrentar o momento da morte dos seus pacientes, e, para isso, são fundamentais a competência e o reconhecimento dos limites das terapias disponíveis.

Isso está claro nas falas dos discentes pesquisados:

[...] é preciso ter noção de limite entre intervenção e curso natural da vida, ter a capacidade de perceber que às vezes, por mais que você faça bem o seu trabalho, a natureza tem sua própria programação (Paulo 21 anos).

Ver a morte como uma passagem. Ter ciência que eu fiz tudo que estava ao meu alcance (Paula, 23 anos).

Apesar de tantos conhecimentos, muitas vezes não somos capazes de conseguirmos "salvar" a vida do paciente, porém devemos dar sempre o melhor de nós (Laura, 23 anos).

Geralmente a morte ocorre em hospitais visando ao processo de cura, e assim o paciente com doença terminal é visto como um fracasso, sendo comum pensar que o importante é vencer a doença a qualquer custo. Dessa forma, vencer a morte é vencer um adversário ${ }^{3}$. 
Quando admitimos o medo que temos da morte, assumimos o medo da vida, ao mesmo tempo que passamos a reconhecer a grandeza de viver e o valor que isso representa. Nesse processo, aceitamos a precariedade da existência e o risco sempre presente de perda definitiva de nós mesmos e daqueles que amamos e conseguimos assumir a angústia da perda ${ }^{23}$.

\section{Limites do curso em relação à morte}

A temática da morte pode ser explicada de forma biológica ou ser discutida de forma plural e interdisciplinar. O professor deve refletir naturalmente e de forma sensível e possibilitar a percepção da transcendência humana. Educar com a consideração da dimensão da transcendência humana é educar para livrar o estudante do medo da morte , $^{5,716,22}$.

A morte é um tema discutido pelos profissionais da saúde, e muitas dessas discussões abrangem questões técnicas sobre como realizar procedimentos corretos e administrar os medicamentos. Entretanto, poucos são os espaços em que se questionam os sentimentos $\mathrm{e}$ as percepções diante da morte ${ }^{3}$.

As DCN referentes ao curso de Medicina oficializaram o acompanhamento do processo de morte como habilidade a ser desenvolvida no ensino médico ${ }^{15}$, todavia as escolas ainda encontram dificuldades para incluir o tema na grade curricular. Entre os fatores para essa dificuldade, está a qualificação dos docentes para discutir sobre o assunto com os estudantes, uma vez que falar da morte remete à própria morte, trazendo angústia e medos. Contudo, é imprescindível despertar a reflexão sobre os limites do saber médico para que seja possível a criação de um espaço além do saber biológico que capacite também os docentes ${ }^{24}$.

Visualiza-se que a dificuldade de inclusão do desenvolvimento da competência e da habilidade para lidar com a morte na formação acadêmica não é um fato acidental do ensino medico, estando implicadas questões epistemológicas que embasam a biomedicina, que remetem ao enigma de lidar com a dor, o sofrimento e a morte ${ }^{24}$.

Vontade de estar mais capacitada (Paula, 22 anos).

Busquei compreender mais a morte de forma a me preparar melhor, apesar de tantos conhecimentos médico recebidos no curso, muitas vezes não somos capazes de conseguirmos "salvar" a vida do paciente, porém devemos dar sempre o melhor de nós (João, 19 anos).

Acho que o curso devia preparar melhor profissionalmente para lidar com a morte (Mariana, 24 anos).

Com base nos relatos, este estudo mostrou que são necessários debates sobre a morte e o morrer durante a graduação, para que os estudantes de Medicina se sintam preparados para vivenciar a morte de pacientes e realizar a comunicação aos familiares.

A terceira categoria foi a humanização, que apresentou duas subcategorias: relação médico- paciente e cuidados paliativos.

A formação médica, para seu pleno exercício profissional, necessita unir ciência e formação humanista ${ }^{20}$. Para tal, o currículo médico foi atualizado por meio das $\mathrm{DCN}^{11}$ que contêm disciplinas baseadas na formação humanista, como cuidados paliativos, psicologia, relações humanas, bioética, entre outras ${ }^{6,21-24}$.

A humanização valoriza o ser humano e oportuniza a autonomia e a ampliação de sua capacidade de ver e modificar o meio em que vive, por meio da responsabilidade com a criação de vínculos solidários coletivamente nos processos de produção de saúde. Uma das ferramentas usadas no processo da humanização é a clínica ampliada que possibilita o desenvolvimento de uma clínica humanizada. Essa clínica contribui com uma abordagem do adoecimento e do sofrimento, que considera a singularidade do sujeito e a complexidade do processo saúde/doença ${ }^{25}$.

A abordagem da relação médico-paciente no curso pesquisado acontece em três disciplinas do eixo de desenvolvimento pessoal, durante o ciclo básico, sendo posteriormente orientada pela conduta dos professores das demais disciplinas, levando-os a diversas posturas ${ }^{26}$. Geralmente, espera-se que eles possuam em sua experiência pessoal comportamentos e atitudes que os predisponham à humanização e que sejam aplicados na vida de estudante e do profissional ${ }^{16,17,27}$.

Nesta pesquisa, muitos depoimentos que comprovam o despertar em relação ao processo de humanização: Vivenciar a morte durante o curso aumentou a minha
sensibilidade e a vontade de se preparar melhor para lidar com a
morte (Joana, 21 anos).

Tento me colocar na situação da família afetada, e termos um médico mais humano (José, 22 anos).

Me fez me forçar a ver o paciente como um ser humano (com seus sentimentos, conflitos e sonhos) igual a mim e menos como um boneco cheio de enigmas que eu deveria desvendar (Patrícia, 24 anos).

Os cuidados paliativos são ações que procuram agir na qualidade de vida de pessoas doentes e familiares durante uma doença terminal, e seu ensino no currículo da graduação em Medicina auxilia aos discentes a encarar limitações que enfrentarão em sua vida profissional e também durante a graduação ${ }^{22,28}$.

O trabalho de médicos que lidam com a morte e doenças terminais deve ser realizado em equipe multiprofissional, que deve estar preparada para lidar com sentimentos de medo, angústia e sofrimento tanto dos pacientes como de seus familiares, atuando com equilíbrio e respeito ante a finitude e as necessidades do paciente ${ }^{5,6,14,16}$. A morte é vista como um processo natural que deve ocorrer em seu tempo ${ }^{28}$.

Observam-se, nas falas dos discentes, afirmações que remetem a esse cuidado:

Pude perceber como a morte às vezes é necessária, principalmente em pacientes que vivem em sofrimento (Ana, 21 anos).

Passei a considerar mais a dor do paciente e aliviar o sofrimento mesmo em situação de morte iminente (Carlos, 24 anos).

Passei a ter mais atenção e carinho com pacientes em estado crítico, mais paciência e atenção nos cuidados com o paciente (Feliciana, 23 anos).

Essas afirmações remetem ao aprendizado, durante o curso, dos aspectos da humanização ligados à relação médico-paciente e aos cuidados paliativos. 


\section{CONSIDERAÇÕES FINAIS}

No Brasil, os cursos médicos vêm buscando trabalhar com situações que aproximam os estudantes de vivências necessárias para melhor significar a morte, com ações que podem influir na maneira de pensar do futuro profissional perante a terminalidade da vida do paciente e o agir com os familiares.

O estudo mostrou que os discentes modificaram sua visão da morte após a vivência no curso, tanto em relação à morte do outro como à sua própria. A vivência da morte despertou a atenção dos discentes para o tema, de modo a aproximá-los, no cotidiano, do fenômeno e revelar a importância dele para a formação dos futuros profissionais. Isso trouxe a percepção da necessidade de ampliar discussões e adquirir novos conhecimentos durante a graduação.

Apesar de existirem no curso estudado disciplinas como Comunicação e Habilidades, Ética e Relações Pessoais, percebeu-se a necessidade de maiores investimentos em relação ao tema abordado, tanto para docentes como para discentes, que repercutirão positivamente na formação de todos e no tratamento com pacientes e familiares.

\section{REFERÊNCIAS}

1. Santos FS. Perspectivas históricos culturais da morte. In: Santo FS, organizador. A arte de morrer: visões plurais. Bragança Paulista: Comenius; 2009. V.

2. Caparroz AD, Vieira DA, Popim RC. A morte no cotidiano da graduação: um olhar do aluno de medicina. Interface 2015;19(55):1207-19.

3. Azeredo NSG, Rocha CF, Carvalho PRA. O enfrentamento da morte e do morrer na formação de acadêmicos de Medicina. Rev. bras. educ. med. 2011;35(1):37-43.

4. Rodrigues JC. A morte numa perspectiva antropológica. In: Santo FS, organizador. A arte de morrer: visões plurais. Bragança Paulista: Comenius; 2009. v. 1.

5. Weill PG. As fronteiras da evolução e da morte: os limites de transformação da energia no homem. 6. ed. Petrópolis: Vozes; 1999.

6. Goswami A. Consciência quântica: uma nova visão sobre o amor, a morte e o sentido da vida. São Paulo: Aleph; 2018.

7. Saporetti LA. Espiritualidade em cuidados paliativos. In: Santo FS, organizador. A arte de morrer: visões plurais. Bragança Paulista: Comenius; 2009. v. 2.

8. Rodrigues Gomes, AM. A espiritualidade no aproximar da morte. Enferm. glob. 2011;(2):1-9 [acesso em 10 jul 2019]. Disponível em: http://scielo.isciii.es/pdf/eg/v10n22/pt_reflexiones2.pdf.

9. Correia DS, Bezerra MES, Lucena TS, Farias MSJA, Freitas DA, Riscado JLS. Cuidados paliativos: importância do tema para discentes de graduação em Medicina. Rev. bras. educ. med. 2018;42(3),78-86.

10. Santos MA, Aoki FCOS, Oliveira-Cardoso EA. Significado da morte para médicos frente à situação de terminalidade de pacientes submetidos ao transplante de medula óssea. Ciênc. Saúde Colet 2013;18(9:2625-34.

11. Kübler-Ross E. Sobre a morte e o morrer. São Paulo: Martins Fontes; 1996.

12. Hayasida NMA, Assayag RH, Figueira I, Matos MG. Morte e luto: competências dos profissionais Rev. bras. ter. cogn. 2014;10(2):112-21.

13. Kovacs MJ. Educadores e a morte. Psicol. Esc. Educ. 2012;16(1):71-81.

14. Lima MGR, Nietsche EA, Santos SC, Teixeira JÁ, Bottega JC, Nicola
GDO et al. Revisão integrativa: um retrato da morte e suas implicações no ensino acadêmico. Rev. Gaúcha Enferm. 2012;33(3),190-7.

15. Brasil. Ministério da Educação. Resolução no 3, de 20 de junho de 2014 [acesso em: 20 jan 2018]. Disponível em: http://www.fmb.unesp. br/Home/Graduacao/resolucao-dcn-2014.pdf.

16. Lino CA, Augusto KL, Oliveira RAS, Feitosa LB, Caprara A. Uso do protocolo Spikes no ensino de habilidades em transmissão de más notícias. Rev. bras. educ. med. 2011;35(1):52-57.

17. Cruz CO, RieraII R. Comunicando más notícias: o protocolo SPIKES. Diagn. Tratamento 2016;21(3):106-8.

18. Santos MRC, Lins L, Menezes MS. As intermitências da morte no ensino da ética e bioética. Rev. bioet. 2018;26(1):135-44.

19. Malheiros B.T, Metodologia de pesquisa em educação. Rio de Janeiro: LTC; 2011.

20. Santos TF, Pintarelli VL. Educação para o processo do morrer e da morte pelos estudantes de Medicina e médicos residentes. Rev. bras. educ. med. 2019;43(2):5-14.

21. Kerr AM, Biechler M, Kachmar U, Palocko B, Shaub T. Confessions of a reluctant caregiver palliative educational program: using readers' theater to teach end-of-life communication in undergraduate medical education. Health Commun. 2018;27:1-9.

22. Quintana AM. Morte e formação médica: é possível a humanização. In: A arte de Morrer: visões plurais. vol 2. São Paulo: Editora Comenius. 2009.

23. Bigheto AC, Incontri D. A religiosidade humana, a educação e morte. In: Santo FS, organizador. A arte de morrer: visões plurais. Bragança Paulista: Comenius; 2009. v. 1.

24. Silva GSN, Aires JRCM. O médico e os desafios de cuidar diante da Morte. In: Santo FS, organizador. A arte de morrer: visões plurais. Bragança Paulista: Comenius; 2009. v. 3.

25. Farias MSJA, Correia DS, Taveira, MGMM, Vilela RQB. Extended clinic in the family health strategy by medical students. International Journal of Medical Science and Clinical Inventions 2016; 3:1803-7.

26. Universidade Federal de Alagoas. PPC Medicina 2006 [acesso em 20 jan. 2018]. Disponível em: http://www.ufal.edu.br/unidadeacademica/ famed/graduacao/medicina/projeto-pedagogico/ppc-medicina/view.

27. Dell Amore Filho E, Dias RB, Toledo Jr ACC. Ações para a retomada do ensino da humanização nas escolas de Medicina. Rev. bras. educ. med. 2018;42(4):14-28.

28. Correia DS, Bezerra MES, Lucena TS, Farias MSJA, Freitas DA, Riscado JLS. Cuidados paliativos: importância do tema para discentes de graduação em Medicina. Rev. bras. educ. med. 2018;42(3):78-86.

\section{CONTRIBUIÇÃO DAS AUTORAS}

Divanise Suruagy Correia elaborou, coordenou e supervisionou a pesquisa e análise dos dados. Contribuiu em todas as sessões de elaboração do artigo. Marias das Graças Monte Mello Taveira contribuiu na análise dos dados e em todas as sessões de elaboração do artigo. Andrea Marques Vanderlei Ferreira Andrea Marques Sandra Lopes Cavalcanti supervisionaram a aplicação da pesquisa e análise dos dados, contribuindo na elaboração dos resultados do artigo. Raissa Ruperto Souza Chagas e Cecilia Frazão Castro participaram da coleta e análise

\begin{tabular}{l|l} 
REVISTA BRASILEIRA DE EDUCAÇÃO MÉDICA \\
\hline $44(1)$ : e013; 2020
\end{tabular} 
dos dados contribuindo na elaboração da revisão de literatura para artigo.

\section{CONFLITO DE INTERESSES}

Não há conflitos de interesses.

\section{ENDEREÇO PARA CORRESPONDÊNCIA}

Divanise Suruagy correia

E-mail: divanisesuruagy@gmail.com

Endereço: Rua D. Vital 85 Farol CEP 57051-200 Maceió Alagoas 